\title{
Method and Electrochemical Biosensor for Detection of Copper in Wine
}

\author{
LILIANA NOROCEL*, GHEORGHE GUTT \\ Stefan cel Mare University of Suceava, Faculty of Food Engineering, 13 Universitatii Str.,720229, Suceava, Romania
}

\begin{abstract}
The developed biosensor is based on the electrochemical signal of the complex formed between the ligand used (glycine) and copper(II) ions. The developed electrochemical method is quick, inexpensive, easy to apply, and has shown good selectivity for copper ions. In this research, a linear response for copper ions was obtained in the concentration range of $0.2 \mathrm{mg}$ to $1 \mathrm{mg} / \mathrm{L}$, which largely covers the area of copper ion concentrations in wine. The achieved sensitivity was 11.05E-05 and the limit of detection (LOD) was 0.041 ppm. The biosensor with screen printed electrodes has been successfully used to detect copper ions in wine. A comparative study between the developed portable biosensor and ICP-MS analysis results of the same samples showed similar results.
\end{abstract}

Keywords: biosensor, copper, screen printed electrodes, glycine

Information on the quantity of the various wine components at all the stages of winemaking allows producers to control the technological process and to obtain a high-quality wine with a specific taste, bouquet, color, flavor and clarity [1].

Wine quality depends on the chemical composition and among these components the concentration of inorganic ion in wine being of great interest [2, 3]. In some cases, the presence of heavy metal traces is related to the quality of the final product and can lead to some defects [2]. The presence of these metal contaminants in wines may be due to several endogenous and exogenous factors [4]. The mineral content of wine depends on the soil, location, grape variety, weather or environmental conditions, and wine practices [5].

Some heavy metals, such as copper, form insoluble salts and induce additional form of casse. Copper(II) can contribute to the oxidative browning of wine, a phenomenon that becomes visible only after bottling. Knowledge regarding the presence of the chemical compound of copper in wine rather than knowledge of its total concentration may be the best indicator of wine oxidation [6]. Copper content is significantly reduced during alcoholic fermentation, however, depending on the initial metal concentration, this decrease may not be sufficient to protect the wine from a possible copper casse [7].

Copper (II) forms stable complexes [8] with amino acids through chelation. In recent years, several studies have reported on the use of amino acids such as L-cysteine, the glycine-histidine complex for the determination of copper ions based on electrochemical detection $[9,10]$. Glycine (Gly) is one of the simplest amino acids that can bind copper in a dimeric form [11].<smiles>NCC(=O)O</smiles>

Glycine
Fig. 1. Copper glycinate complex formation

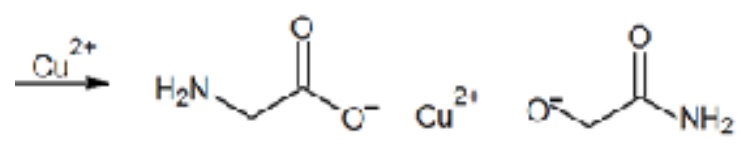

Copper glycinate

Mostexisting techniques used for trace analysis of heavy metals include classic methods such as spectroscopy and chromatography, which can detect cations at very low concentrations. These methods are costly and difficult or even impossible to use in situ analysis. Recentstudies show increasing interest in sensors [12], among which the electrochemical sensors and biosensors can provide important advantages through the high stability and reproducibility, high sensitivity with low detection limits, and linear responses for selected element $[13,14]$.

Voltammetry is one of the most used electrochemical detection techniques. Several variations of voltammetry have been developed, and these include: cyclic voltammetry, stripping voltammetry, square-wave voltammetry, linear sweep voltammetry, alternating current voltammetry, normal pulse voltammetry and differential pulse voltammetry [15]. Of these techniques, cyclic voltammetry has been previously applied by Popescu et al. (2011) to calculate the diffusion coefficient for the $\mathrm{Cu}^{2+} \mathrm{Cu}^{+}$redox couple [16].

The purpose of this study was to develop a simple and rapid method that uses an electrochemical portable biosensor for the quantification of copper ions in wine. In order to select the copper ions from the wine sample, glycine was used as a biological element and agarose was chosen as an immobilization agent. The efficiency of the developed method and related biosensor used in the analysis of copper cations concentration was studied based on sensitivity, detection limit, and response time. The performance of the proposed method and of the developed portable biosensor was verified through comparison against the results of an ICP-MS analysis.

\section{Experimental part \\ Materials and methods}

Glycine, agarose and copper sulfate used were from Sigma Aldrich, and the wine samples were purchased from a wine cellar in the city of Suceava. 5 samples of white wine and 5 samples of red wine were used.

For electrochemical detection, carbon based Pine Research screen printed electrodes (SPE) have been used. SPE contain a working carbon-electrode, a counter carbonelectrode, and a silver/silver chloride reference electrode $(\mathrm{Ag} / \mathrm{AgCl})$. The screen printed electrode dimensions of the

\footnotetext{
* email: liliana.norocel@fia.usv.ro
} 
RRPE1001C type were $15 \times 61 \times 0.36 \mathrm{~mm}$, with a surface of the working electrode of $2.0 \mathrm{~mm}$ diameter.

\section{Apparatus}

Electrochemical measurements were performed using a Metrohm Autolab potentiostat/ galvanostat PGSTAT204 at a $100 \mathrm{~Hz}$ frequency with an upper vertex potential of 0.6 $\mathrm{V}$, a lower vertex potential of $-0.6 \mathrm{~V}$, and a rate scan of $0.1 \mathrm{~V} /$ S. ICP-MS analysis was performed with an Agilent Technologies 7500 Series Spectrometer (Agilent, USA) according to the working methodology described in the Compendium of International Analysis of Methods - OIV Multielemental Analysis Using ICP-MS, OIV-MA-AS323-07: R2010, Type II Method- (OIV-Oeno 344-2010).

\section{Sample preparation}

Solutions of $5 \%$ glycine and $0.5 \%$ agarose were freshly prepared and then immobilized on the working electrode of the SPE in a ratio of 1:1. After drying, the electrodes were introduced into cells with $10 \mathrm{~mL}$ of artificial solutions having different concentrations of copper ions as well as in real wine samples using cyclic voltammetry for analysis.

\section{Results and discussions}

Cyclic voltammograms were performed for five copper solutions of $0.2 ; 0.4 ; 0.6 ; 0.8 ; 1 \mathrm{mg} / \mathrm{L}$ (fig. 2). Following that 10 samples of wine were analyzed and the data compared to the ICP-MS analysis of the same samples.

Electrochemical measurements were made and the maximum and minimum intensities of the resulted voltammograms were used to obtain regressions in order to observe the linearity of the copper ions selectivity (fig. 3).

According to Faraday's law, the mass of the substance deposited or dissolved on the electrodes of an electrochemical system is directly proportional to the amount of electricity passing through the electrochemical

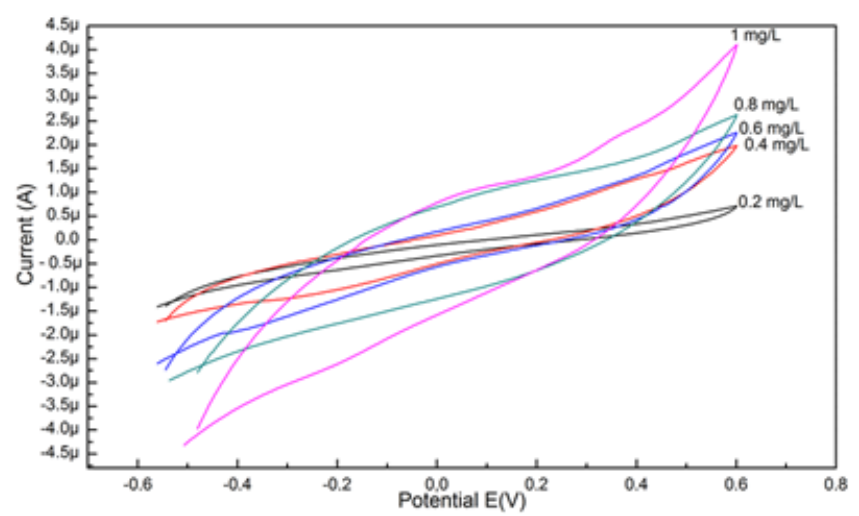

Fig. 2. Cyclic voltammograms of artificial copper solution

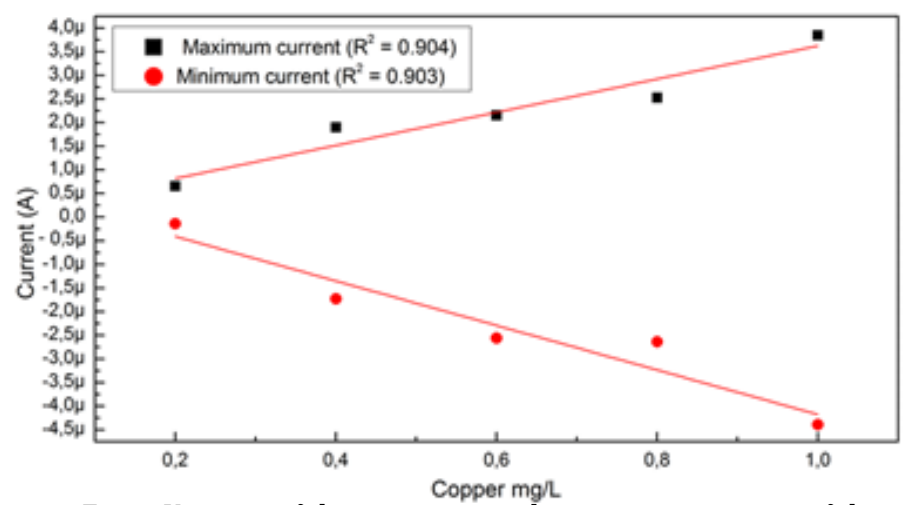

Fig. 3. Variation of the maximum and minimum intensities of the resulting cyclic voltammogram for copper solutions cell [17]. Correspondingly, the mass of copper ions deposited on the electrode during the electrochemical measurements was calculated, and the resulting concentration, based on the existing quantity, is shown in figure 4.

$$
m=k \times i \times t
$$

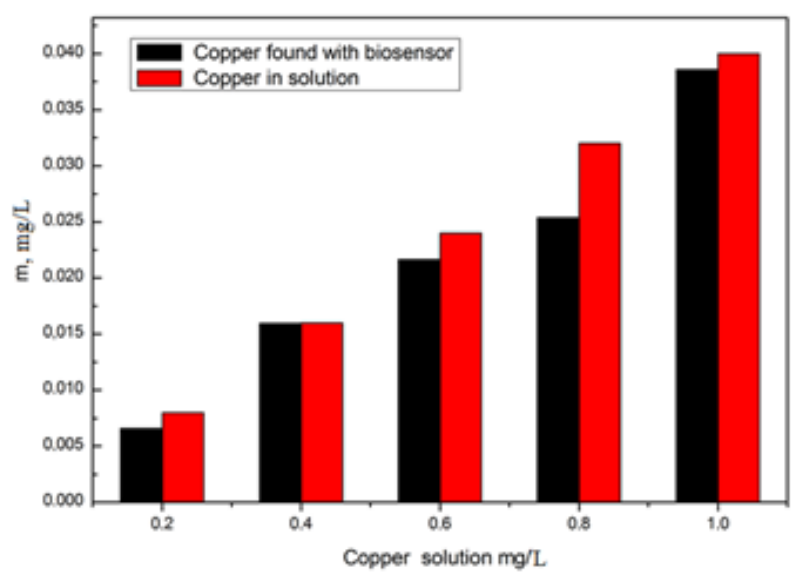

Fig. 4. Quantity of copper deposited on SPE, depending on the existing copper concentration

As figure 4 shows, the developed method has a good selectivity for copper ions, with an average deposition efficiency of $89.58 \%$. Very close values between the quantity of copper deposited on the electrode and the existing copper concentration in the cell were obtained for the solution of $0.4 \mathrm{mg} / \mathrm{L}$ copper.

\section{Analytical performance of the biosensor}

The analytical performances of the biosensor were evaluated based on sensitivity, detection limit and biosensor response time, the results are shown in table 1.

Sensitivity was calculated using eq. (2):

$$
\text { Sensitivity }=\frac{m}{A}
$$

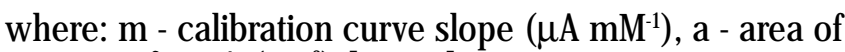
active surface $A\left(\mathrm{~cm}^{2}\right)[17,18]$.

The blank detection limit (LoB, eq. 3) and the limit of detection (LoD) of the proposed biosensor are terms used to describe the lowest concentration of an analyte that can be reliably measured by an analytical procedure.

$$
\mathrm{LOB}=\text { mean }_{\text {blank }}+\mathrm{SD}_{\text {blank }}
$$

where SD = Standard deviation .

LoD (eq. 4) is determined by using both the measured LoBs and the test replicates of a sample know $n$ to contain a low analyte concentration [19]. The mean and SD of the low concentration test were calculated as follows:

$$
\mathrm{LOD}=\mathrm{LOB}+\mathrm{SD}_{\text {low }} \text { concentration sample }
$$

The analysis of copper solutions indicated a good sensitivity and a low detection limit of the method developed to determine the copper ions in wine. In terms

Table1

PERFORMANCE PARAMETERS OF THE BIOSENSORS

\begin{tabular}{|c|c|}
\hline Characteristic & Values \\
\hline Slope curve & $3.508 \mathrm{E}-06$ \\
\hline Sensitivity & $11.17 \mathrm{E}-05$ \\
\hline Limit of detection & $0.04139 \mathrm{mg} / \mathrm{L}$ \\
\hline Response time & $30 \mathrm{~s}$ \\
\hline
\end{tabular}


of response time, the biosensor conforms to the conditions of a rapid analysis.

Comparison between the electrochemical biosensor results and an ICP-MS analysis

Figure 5 shows the differences between the results of the analysis of copper in wine samples using the proposed biosensor method and the concentrations of copper measured in the samples by ICP-MS.

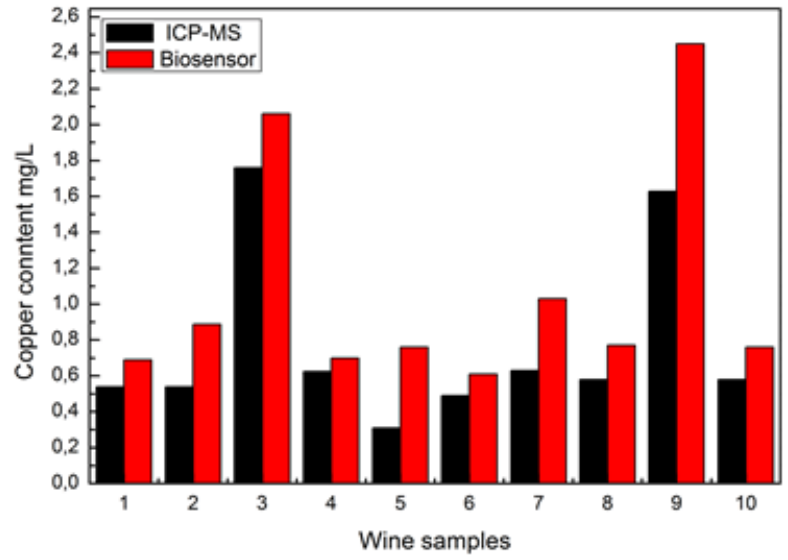

Fig. 5. Copper content in wine samples, determined by ICP-MS and developed biosensor

The performance of the new method for determining copper content in wine was compared to that of ICP-MS. 10 samples of wine were analyzed and the results compared. The difference in percent $(\Delta \%)$ is given by eq. 5:

$$
\Delta \%=100 \frac{C_{A}-C_{B}}{\left(C_{A}+C_{B}\right) \div 2}
$$

where: $C_{A}$ is the concentration determined by ICP-MS and $C_{B}$ is the concentration determined by the biosensor.

The maximum value of this function is $\pm 200 \%$. The value $\Delta \%=0$ denotes a perfect match of the two analytical values, while values close to $\pm 200 \%$ indicate that there is no similarity between the values. A positive value of $\Delta \%$ shows that the concentration of $\mathrm{Cu}(\mathrm{II})$ is higher in the case of ICP-MS and a negative value indicates a higher concentration in the case of the biosensor determination than of the ICP-MS analysis [20].

The difference between the two methods of analysis of copper traces has negative values, as observed in figure 6 . Values are between -11.19 and -84.21, and all 10 samples have an average value of -47.7 .

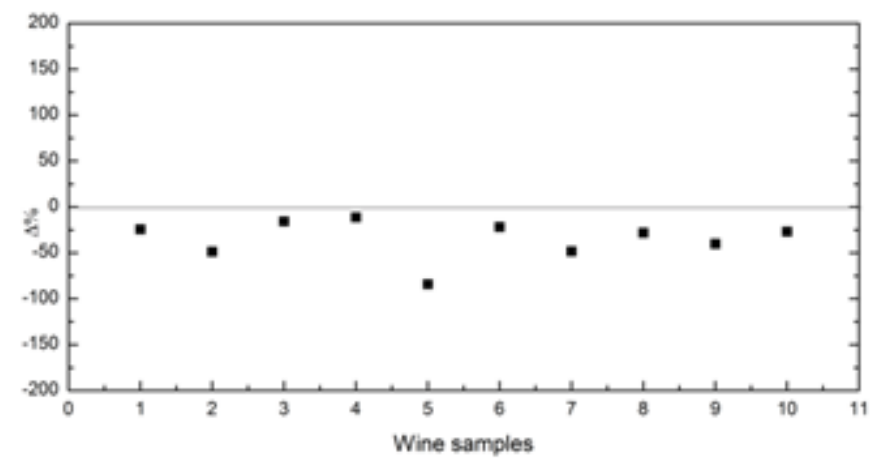

Fig. 6. The difference in percent ( $\mathrm{A} \%)$ between the values of de developed biosensor method and the ICP-MS analysis

By comparing the results obtained by ICP-MS with the results obtained using the method and the developed biosensor, a higher performance is observed for the latter.

\section{Conclusions}

The proposed method for determining the concentration of copper ions in wine and the electrochemical biosensor used in this method have proven to be performant analytical means. In the experimental study glycine has shown good selectivity for copper ions and can be recommended as a good recognition element. Moreover, the immobilization method led to an enhancement of their selectivity.

The developed biosensor has a high sensitivity, a detection limit that places it in the range of possible copper ion concentrations in wine and a low response time.

Comparative analysis between the results of ICP-MS and the biosensor showed a good fit of the methods, which suggests the possibility of application for the in situ detection of copper concentration in wine.

\section{References}

1.STAFILOV T., KARADJ OVA I., Maced J Chem Chem En, Vol. 28, No. 1, 2009, pp. 17-31.

2.SADAK 0., et al., 2017, Biosens. Bioelectron, 89, 2017, 430-436.

3.BOEV, I. et al., Goce Delèev University, Stip, Republic of Macedonia 2 Faculty of Natural and Technical Sciences, 2010.

4.COMEAUX, R., NOVOTNY, P., Biosensors-Properties, materials and application, Biotechnology in Agriculture, Industry and Medicine Series, 2009, 98-117.

5.KAILAS H. K., , Int. J. Pharm. Pharm. Sci., Volume 4, Issue 10, 22292233 Research Article, 2015.

6.MOISE, G. (2015). Scientific Papers Series-Management, Economic Engineering in Agriculture and Rural Development, 15(3), 201-204..

7.ROUSSEVA, M., KONTOUDAKIS, N., SCHMIDTKE, L. M., SCOLLARY, G. R., \& CLARK, A. C. Food chem, 203, 2016, 440-447.

8.ALI, K. J., \& HAMEED, N. A. R. Acta Chim Pharm Indica, 4(3), 2014. 9.VASILESCU, I., LITESCU, S., PENU, R., RADU, G. L., Rev. Chim.(Bucharest), 58, no. 12, 2007, p. 1161-1166.

10.YANG, W., JARAMILLO, D., GOODING, J. J ., HIBBERT, D. B., ZHANG, R., WILLETT, G. D., \& FISHER, K. J., Chem. Commun., (19), 2001, 1982-1983.

11.LY, N. H., SEO, C., \& J OO, S. W. Sensors, 16(11), 2016, 1785.

12.COSTA SILVA L. M., et al, State of the Art in Biosensors Environmental and Medical Applications, InTech, Dr. Toonika Rinken (Ed.), ISBN: 978-953-51-1035-4, 2013, InTech, DOI: 10.5772/55617.

13.FARIDBOD, F., GUPTA, V. K., \& ZAMANI, H. A. Int. J. Electrochem, 2011.

14.ANICAI, L., STOICA, C., VLADUT, C., NEGRU, A., TEULON, J. M., ODORICO, M., ENACHESCU, M., Rev. Chim. (Bucharest), 66, no. 10, 2015, p. 1639-1644.

15.FAROOQI, M.O., TAIMOOR, AQEEL A., AL-SHAHRANI, S., BALEANU, D., RATHER, S.U., Rev. Chim.(Bucharest), 66, no. 4, 2015, p. 499-502. 16.POPESCU, A. M., CONSTANTIN, V., COJOCARU, A., OLTEANU, M. Rev. Chim.(Bucharest), 62, no. 2, 2011, p. 206-211.

17.LU, X., ZHANG, H., NI, Y., ZHANG, Q., \& CHEN, J., Biosens. Bioelectron, 24(1), 2008, 93-98.

18.BALAKRISHNAN, S. R., HASHIM, U., LETCHUMANAN, G. R., KASHIF, M., RUSLINDA, A. R., LIU, W. W., \& POOPALAN, P., Sens Actuators A Phys, 220, 2014, 101-111.

19.AFRAZ, A., RAFATI, A. A., \&NAJAFI, M., Mater. Sci. Eng. R: C, 44, 2014, 58-68.

20.ARMBRUSTER, D. A., \& Pry, T., Clin Biochem Rev, 29(Suppl 1), 2008, S49-52.

Manuscript received: 21.11 .2017 